\title{
Phase 2 Randomized Clinical Study of Netarsudil Ophthalmic Solution in Japanese Patients with Primary Open-Angle Glaucoma or Ocular Hypertension
}

\author{
Makoto Araie $\cdot$ Kazuhisa Sugiyama $\cdot$ Kenji Aso $\cdot$ Koji Kanemoto • \\ Kalyani Kothapalli · Casey Kopczynski · Michelle Senchyna • \\ David A. Hollander
}

Received: December 23, 2020 / Accepted: January 19, 2021 / Published online: February 24, 2021

(C) The Author(s) 2021

\begin{abstract}
Introduction: Netarsudil reduces intraocular pressure (IOP) by increasing aqueous outflow through the trabecular meshwork (TM) pathway and decreasing episcleral venous pressure. The primary objective of this phase 2 study was to evaluate ocular hypotensive efficacy and safety of three netarsudil concentrations $(0.01 \%, 0.02 \%$, and $0.04 \%)$ relative to its placebo over 4 weeks in Japanese patients with primary open-angle glaucoma (POAG) or ocular hypertension (OHT).
\end{abstract}

Supplementary Information The online version contains supplementary material available at https:// doi.org/10.1007/s12325-021-01634-9.

M. Araie $(\bowtie)$

Kanto Central Hospital of the Mutual Aid

Association of Public School Teachers, Tokyo, Japan

e-mail: m.araie-tky@nifty.com

\section{K. Sugiyama}

Department of Ophthalmology, Kanazawa

University Graduate School of Medical Science,

Kanazawa, Ishikawa, Japan

K. Aso - K. Kanemoto

Aerie Pharmaceuticals Ireland Ltd. (Japan Branch),

Tokyo, Japan

K. Kothapalli

Statistics and Data Corporation, Tempe, AZ, USA

C. Kopczynski · M. Senchyna · D. A. Hollander

Aerie Pharmaceuticals, Inc., Irvine, CA, USA
Methods: Patients were randomized to one of four treatment arms, netarsudil ophthalmic solution $0.01 \%, 0.02 \%, 0.04 \%$, or placebo, and treated once-daily (QD) in the evening (Р.м.) for 4 weeks. The primary efficacy variable was mean diurnal IOP (average of diurnal time points at 9 A.M., 11 A.M., and 4 P.м.) at week 4.

Results: A total of 215 patients were randomized and 207 (96.3\%) completed the study. The mean of mean diurnal IOP at baseline ranged from 20.28 to $21.14 \mathrm{mmHg}$ across groups. At week 4 , least squares (LS) mean of mean diurnal IOP adjusted for baseline was 16.53, 15.82, 16.06 , and $18.94 \mathrm{mmHg}$ in the netarsudil $0.01 \%, 0.02 \%, 0.04 \%$, and placebo groups, respectively, demonstrating the superiority of netarsudil (all concentrations) over placebo. At week 4, mean reduction (mean percentage reduction) from baseline in mean diurnal IOP was 4.10 (19.8\%), 4.80 (23.5\%), 4.81 (23.8\%), and $1.73 \mathrm{mmHg}(8.2 \%)$, respectively, demonstrating statistically significant reductions $(p<0.0001)$ in all netarsudil concentrations over placebo. Adverse events (AEs) occurred in a concentration-dependent manner, and the incidence of ocular AEs was 34.5\%, 42.6\%, $68.6 \%$, and $9.1 \%$ in the netarsudil $0.01 \%$, $0.02 \%, 0.04 \%$, and placebo groups, respectively. The most frequently reported $\mathrm{AE}$ was conjunctival hyperemia, with an incidence of $23.6 \%$, $37.0 \%, 56.9 \%$, and $1.8 \%$, respectively. No serious AEs were reported. 
Conclusion: Netarsudil ophthalmic solutions $0.01 \%, 0.02 \%$, and $0.04 \%$ dosed QD (Р.м.) demonstrated superiority to placebo in terms of hypotensive effectiveness at week 4 and were found to be safe and generally well tolerated. Netarsudil $0.02 \%$ QD provided an optimal efficacy and safety profile for the treatment of Japanese patients with POAG or OHT.

Trial Registration: NCT03844945.

Keywords: Conjunctival hyperemia; Glaucoma; Intraocular pressure; Netarsudil; Rho-associated protein kinase

\section{Key Summary Points}

Why carry out this study?

Glaucoma is the most common cause of irreversible blindness affecting around 4.65 million people in Japan and more than 64 million people worldwide. The incidence of glaucoma is expected to increase to more than 112 million by 2040 .

Rho-associated protein kinase (ROCK) inhibitors represent a new therapeutic class for glaucoma. Netarsudil is a novel ROCK inhibitor lowering the intraocular pressure (IOP) by increasing the aqueous humor outflow through the trabecular meshwork (TM) pathway.

The study evaluates the hypotensive efficacy and safety of three different concentrations $(0.01 \%, 0.02 \%$, and $0.04 \%$ ) of netarsudil ophthalmic solution relative to placebo over a 4 -week period in Japanese patients with primary openangle glaucoma (POAG) or ocular hypertension (OHT) to determine the optimal concentration of netarsudil ophthalmic solution for the population.

\section{What was learned from the study?}

Netarsudil $0.01 \%, 0.02 \%$, and $0.04 \%$ once daily (in evening) were superior to placebo in terms of lowering mean diurnal IOP after 4 weeks of treatment $(16.53,15.82$, 16.06 , and $18.94 \mathrm{mmHg}$, respectively, $p<0.0001)$.

The incidence of ocular adverse events (AEs) was $34.5 \%, 42.6 \%$, and $68.6 \%$ in the netarsudil $0.01 \%, 0.02 \%$, and $0.04 \%$ groups, respectively. The most common ocular AE was conjunctival hyperemia with the highest incidence in netarsudil $0.04 \%$ (56.9\% subjects) followed by netarsudil $0.02 \%$ (37.0\% subjects), and netarsudil $0.01 \%$ (23.6\% subjects) groups.

Netarsudil $0.02 \%$ once daily provided the optimal hypotensive efficacy and safety profile for the treatment of Japanese population with POAG or OHT.

\section{DIGITAL FEATURES}

This article is published with digital features, including a summary slide, to facilitate understanding of the article. To view digital features for this article go to https://doi.org/10.6084/ m9.figshare.13606589.

\section{INTRODUCTION}

Glaucoma, a progressive degenerative optic neuropathy, causes characteristic loss of visual field and is characterized by functional and mechanical abnormalities of the eyes (i.e., death of retinal ganglion cells and related damage to the optic nerve) [1]. As the leading cause of irreversible blindness worldwide, glaucoma impacts more than 64 million people (aged 40-80 years) worldwide and the number is expected to escalate to 112 million by 2040 [2]. In Japan, glaucoma is a major cause of blindness affecting approximately 4.65 million people [3]. Primary glaucoma is often classified into the two broad categories of primary open-angle 
glaucoma (POAG) and primary angle-closure glaucoma, depending upon the type of angle formed between iris and cornea (wide and open angle or closed/narrow angle). The POAG is further divided on the basis of intraocular pressure (IOP) into POAG with elevated IOP and POAG with IOP within the normal range (normal-tension glaucoma, NTG). In an epidemiologic study conducted in Japan, the prevalence of glaucoma, POAG, and NTG was 5.0\%, 3.9\%, and $3.6 \%$, respectively, which revealed that more than $90.0 \%$ of patients in Japan with POAG had NTG [4, 5]. An approximately fourfold higher incidence of NTG was also reported in the Japanese American population compared to high-tension glaucoma cases [6]. Ocular hypertension (OHT) is defined as a pathological condition without abnormalities in the optic nerve and visual field despite elevated IOP. Although it is a leading risk factor for the development of POAG, its prevalence in Japan was relatively low at $0.8 \%$ [4].

A major risk factor for glaucomatous visual field loss is elevated IOP [7], which is most commonly the result of dysfunction of the trabecular meshwork (TM) outflow pathway (i.e., increase in the stiffness of $\mathrm{TM}$, changes in extracellular matrix deposition or permeability of the inner wall of Schlemm's canal) resulting in decreased aqueous humor outflow to venous circulation $[8,9]$. Currently, IOP reduction via pharmacologic therapies or surgical intervention remains the only reliable treatment for all stages and types of glaucoma [10]. Various studies have reported that every millimeter reduction in IOP significantly delays the disease progression not only in patients with POAG with elevated IOPs but also in patients with NTG [11-14]. Hence, to maintain the quality of vision and quality of life of the patients, it is critically important to diagnose, treat, and reduce the progression of the disorder by selecting the appropriate pharmacotherapy(ies), which must be safe, well tolerated, and effective in lowering IOP for an extended period of time.

There are various pharmacotherapies which lower IOP by either increasing uveoscleral outflow (e.g., prostaglandins and alpha agonists) or decreasing aqueous humor production (e.g., beta blockers, carbonic anhydrase inhibitors, alpha agonists) without specifically targeting the diseased TM pathway [15, 16]. Prostaglandin analogues are often recommended as the first-line therapy, except in special circumstances, because of the overall safety, tolerability, and efficacy profile and once-daily (QD) administration. However, prostaglandins can result in characteristic cosmetic adverse reactions, such as eyelid and iris pigmentation, elongation of the eyelashes, and deepening of upper eyelid sulcus, that may impair the quality of life of patients. Beta blockers, which are positioned after prostaglandin analogues on the basis of ocular tolerability and ocular hypotensive efficacy, have contraindications based on the systemic (e.g., cardiovascular and pulmonary) adverse drug reactions and thus have a significant drawback in treating elderly patients with glaucoma who often have cardiovascular and respiratory comorbidities [3]. Rho-associated protein kinase (ROCK) inhibitors represent a new therapeutic class with a unique mechanism of action. ROCK inhibitors increase aqueous outflow through the TM outflow pathway by decreasing actomyosin-driven cellular contractions, production of fibrogenic extracellular matrix proteins, and cell stiffness to relax TM outflow tissues and lower IOP [17-21]. In Japan, ripasudil hydrochloride hydrate $0.4 \%$ twice daily (BID) is a ROCK inhibitor that is broadly used in clinical practice for the treatment of glaucoma and OHT; however, adverse reactions such as blepharitis or allergic conjunctivitis can lead to the discontinuation of drug treatment at a relatively high rate $[22,23]$. Glaucoma is a chronic and initially asymptomatic disease for which poor adherence to drug treatment is common and reported to be associated with the progression of glaucoma [24]. Hence, there remains a need for new treatment option(s) with once-daily administration that lower IOP by targeting the diseased TM outflow pathway and have a good safety profile without systemic adverse drug reactions.

Netarsudil mesylate (an amino isoquinoline amide) lowers IOP by inhibiting ROCK1 and ROCK2, and has been shown to increase TM outflow facility in mouse [25], monkey [20, 26], and human $[27,28]$ eyes. In addition, it is believed to also reduce episcleral venous 
pressure [20, 28, 29]. Netarsudil ophthalmic solution $0.02 \%$ was approved by the US Food and Drug Administration on December 18, 2017 and by the European Commission in November 2019 for reduction of elevated IOP in patients with POAG or OHT with the recommended dosage of one drop into the affected eye(s) QD in the evening (Р.м.) [30]. It has demonstrated ocular hypotensive activity throughout the day with equal effectiveness in terms of IOP reduction in both nocturnal and diurnal periods [31]. Various clinical studies have shown netarsudil $0.02 \%$ dosed QD to be safe and well tolerated with significant reduction in IOP levels in patients with POAG or OHT including those with lower baseline IOP [28, 32-35]. The drug is expected to have high clinical utility in Japan where patients with POAG and relatively low IOP, including patients with NTG, are prevalent.

In a recent clinical study conducted in the USA on 42 Japanese American patients with POAG or OHT, both netarsudil ophthalmic solution $0.02 \%$ and $0.04 \%$ QD were shown to be safe, generally well tolerated, and efficacious. To further evaluate netarsudil in a larger number of Japanese patients and to confirm the optimum concentration for the Japanese population, the current phase 2 study was conducted to evaluate the hypotensive efficacy and safety of three different concentrations $(0.01 \%, 0.02 \%$, and $0.04 \%$ ) of netarsudil ophthalmic solution relative to placebo over a 4 -week treatment period in Japanese patients with POAG or OHT.

\section{METHODS}

\section{Study Design}

This study was a prospective, double-masked, randomized, placebo-controlled, parallel-group, phase 2 study that evaluated efficacy and safety of three concentrations $(0.01 \%, 0.02 \%$, and $0.04 \%$ ) of netarsudil ophthalmic solution over a 4 -week treatment period in Japanese patients at least 20 years of age with POAG or OHT. The study was conducted at 25 sites in Japan from March 19, 2019 to September 19, 2019 (registered with ClinicalTrials.gov as NCT03844945).
All study-related documents were reviewed and approved by appropriate ethics committees (Table S1 in the supplementary material). The study was conducted in accordance with ethical principles based on the Declaration of Helsinki and the guidance stipulated in Article 14, Paragraph 3, and Article 80-2 of the Pharmaceuticals, Medical Devices and Other Therapeutic Products Act of Japan, Ministry of Health, Labour and Welfare (MHLW) Ordinance on Good Clinical Practice (MHLW Ordinance No. 28 [March 27, 1997]), International Council for Harmonization Guideline E6 (R2), the study protocol, and the standard operating procedures. All patients provided their written informed consent before participating in the study.

The patients attended a total of six study visits, including the screening visit (visit 1 ), qualification visit 1 (visit 2 , after a washout period of pre-study ocular hypotensive medication varying from 5 days to at least 6 weeks; 5 days for muscarinic agonists or carbonic anhydrase inhibitors; 2 weeks for adrenergic agonists; 4 weeks for prostaglandins or $\beta$ adrenoceptor antagonists; 6 weeks for Rho kinase inhibitor), qualification visit 2 /day 1 / baseline (visit 3; 2-7 days after qualification visit 1$)$, and post-treatment visits at week 1 (visit 4 ; day $8 \pm 2$ days), week 2 (visit 5; day $15 \pm 3$ days), and week 4 (visit 6; day $29 \pm 3$ days). Those patients who met the study eligibility criteria at screening visit and qualification visits 1 and 2 were considered eligible to participate in the study. All the eligible patients were enrolled at qualification visit 2 (day 1$)$ and were randomized $(1: 1: 1: 1)$ by a computer-generated randomization list using an interactive web response system to receive the placebo or netarsudil ophthalmic solution $0.01 \%, 0.02 \%$, or $0.04 \%$. The study medication was dosed (one drop) into each eye QD in the evening (between 8 and 10 P.M.), beginning on day 1 and up to and including the evening before week 4 .

Patients and designated study site personnel (investigators, sponsor, monitor, data manager, statistician, and personnel involved in study management) were fully masked to treatment assignments. Patients were permitted to have 
intermittent use of artificial tear lubricant products (a gap of at least 10 min between the use of artificial tear lubricant products and the study medication) and wear contact lenses (a gap of $30 \mathrm{~min}$ between the contact lens wear and instillation of study medication). Patients were prohibited to use any form of ocular hypotensive medications; miotics; epinephrinerelated compounds; carbonic anhydrase inhibitors; $\alpha$ - and $\beta$-adrenoceptor antagonists; muscarinic agonists; ocular prostaglandins analogues; ROCK inhibitors; any corticosteroids containing ocular or systemic drug; or systemic medications known to cause corneal deposits or cornea verticillata.

Procedures included efficacy (IOP) and safety assessments, including ocular symptoms/adverse events (AEs); National Eye Institute Visual Function Questionnaire (VFQ-25); contrast sensitivity (CS) testing; best corrected visual acuity (BCVA); biomicroscopic examinations of the eyelids, conjunctiva, cornea, anterior chamber, iris, pupil, and lens of the eye; dilated ophthalmoscopy examination of the retina, vitreous, macula, choroid, optic nerve, and vertical cup/disc ratio; vital signs (heart rate and blood pressure); and clinical laboratory assessments (urine pregnancy test, blood chemistry, hematology, and urinalysis). The IOP was measured at screening visit, qualification visit 1 , and day 1 and weeks 1,2 , and 4 (9 A.M. $+30 \mathrm{~min}$, 11 A.M. $+30 \mathrm{~min}$, and 4 P.M. $\pm 30 \mathrm{~min})$ at all study visits using a calibrated Goldmann applanation tonometer (the most clinically accurate and the standard tonometer used in the diagnosis and treatment of glaucoma [3]). Two consecutive IOP measurements of each eye were obtained at each time point. If the two measurements differed by more than $2 \mathrm{mmHg}$, a third measurement was obtained. The IOP was recorded as the mean of two measurements or the median of three measurements [36]. AEs were collected from the time of administration until 30 days after the last dose of study medication. The VFQ-25 (Japanese version) and CS testing were done at day 1 ; BCVA and vitals at screening visit, qualification visit 1 , and day 1 and weeks 1, 2, and 4; biomicroscopy at screening visit, qualification visit 1 , and day 1 and weeks 1,2 , and 4 ; dilated ophthalmoscopy at screening visit and week 4; and clinical laboratory tests at screening visit and week 4 .

CS was assessed using the CSV-1000E test at the recommended test distance of $8 \mathrm{ft}(2.5 \mathrm{~m})$, and at the spatial frequencies of $3,6,12$, and 18 cycles/degree. BCVA was measured using a Landolt-C chart or its equivalents, at a distance as per the site's standard practice, with the patient's best correction from the manifest refraction in place. A decrease in BCVA of three lines or more in visual acuity from baseline was defined as clinically significant. The BCVA assessment preceded IOP measurements and the administration of topical anesthetic agents, or any examination requiring contact with the anterior segment. Biomicroscopic abnormal findings were graded on scales of 0 (none) to 3 (severe), or 0-4 (cells and cornea verticillata), and lens status was reported as phakic, pseudophakic, or aphakic; and dilated ophthalmoscopy findings were assessed as 0 (normal) or 1 (abnormal). The cup/disc ratio was scored on a scale of 0.1 to 1.0 in 0.1 increments. A change of 0.2 units from baseline in either eye was considered as clinically significant.

\section{Patients}

Eligible patients had a diagnosis of POAG or OHT in both eyes or POAG in one eye and OHT in another (fellow) eye; age at least 20 years; medicated IOP $14 \mathrm{mmHg}$ or higher in at least one eye and less than $30 \mathrm{mmHg}$ in both eyes at the screening visit; BCVA 0.1 or better in the decimal unit using Landolt-C chart or its equivalent $(+1.0 \log$ MAR or better by Early Treatment of Diabetic Retinopathy Study or $20 / 200$ or better by Snellen chart); and were able and willing to provide signed informed consent and follow study instructions. The unmedicated (post washout) IOP for POAG eyes was at least $15 \mathrm{mmHg}$ and less than $35 \mathrm{mmHg}$ in the study eye and for OHT eyes, it was at least $22 \mathrm{mmHg}$ and less than $35 \mathrm{mmHg}$ in the study eye at qualification visit 1 (9 A.м.) and qualification visit 2 (9 A.M., 11 A.M., and 4 P.M.).

Patients were excluded from entry into the study if they had clinically significant ocular disease; pseudoexfoliation or pigment 
dispersion glaucoma, history of angle closure or narrow angles; ocular hyperemia score of moderate $(+2)$ or severe $(+3)$ at day 1 ; previous intraocular glaucoma or refractive surgery in either eye; ocular trauma within 6 months or ocular surgery or non-refractive laser treatment within 3 months prior to screening; evidence of ocular infection or inflammation in either eye, clinically significant blepharitis, conjunctivitis, keratitis or a history of herpes simplex or zoster keratitis in either eye at screening; any corneal disease or condition in either eye that in the investigator's opinion may have confounded assessment of the cornea; current evidence of corneal deposits or cornea verticillata in either eye; use of ocular medication in either eye within 30 days of screening and throughout the study with the exception of ocular hypotensive medications, lid scrubs, lubricating drops, nonsteroid allergy drops, cataract medicinal treatment, and topical nutritional supplement; mean central corneal thickness greater than $620 \mu \mathrm{m}$ in either eye at screening; any abnormality preventing reliable applanation tonometry of either eye; known hypersensitivity to benzalkonium chloride or excipients of netarsudil ophthalmic solution; or cannot demonstrate proper delivery of the eye drop or in the investigator's opinion unable to deliver the eye drop consistently. Patients were also excluded from the study if they were currently using systemic medications known to cause corneal deposits or cornea verticillata; had clinically significant abnormalities in laboratory tests at screening or clinically significant systemic disease which might have interfered with the study; had participated in any interventional study within 30 days before screening; or had used systemic medication(s) that could have had a substantial effect on IOP within 30 days before screening, or that were anticipated during the study, including any corticosteroidcontaining drug regardless of route of administration. Women of childbearing potential who were pregnant, nursing, planning a pregnancy, or not using a medically acceptable form of birth control were also excluded from the study. All women of childbearing potential must have a negative urine pregnancy test result at the screening examination and must not intend to become pregnant during the study.

\section{Study Variables}

\section{Efficacy Variables}

The primary efficacy variable was mean of mean diurnal IOP at week 4, with mean diurnal IOP calculated by averaging IOP measurements at 9 A.M., 11 A.M., and 4 P.M. for each patient first and then calculating the mean across patients within each treatment group. The secondary efficacy variables were mean of mean diurnal IOP at weeks 1 and 2; mean change and mean percentage change from baseline in mean diurnal IOP at each post-treatment visit; mean, mean change, and mean percentage change in IOP at each post-treatment time point ( 9 A.M., 11 A.м., and 4 P.м.) at each post-treatment visit; and percentage of patients achieving pre-specified mean diurnal IOP, and mean change and mean percentage change in mean diurnal IOP levels.

\section{Safety Variables}

The ocular safety variables were ocular symptoms/AEs; BCVA; objective findings of biomicroscopic examinations; and dilated ophthalmoscopy, including vertical cup/disc ratio measurements. The other safety variables were non-ocular AEs; vital signs; and clinical laboratory evaluations.

\section{Statistical Analysis}

The statistical analyses were conducted using SAS $^{\circledR}$ (SAS Institute, Cary, North Carolina, USA), version 9.4. The intent-to-treat (ITT) population was used for efficacy analyses where the ITT population included all randomized patients who received at least one dose of the study medication.

The analysis of the primary efficacy variable employed an analysis of covariance (ANCOVA) model with mean diurnal IOP at week 4 as the response, baseline mean diurnal IOP as a covariate, and treatment as the main effect, using the ITT population with Monte Carlo Markov chain multiple imputation techniques 
to impute the missing data. The ANCOVA model explains additional variability (i.e., reduces standard error) through inclusion of baseline covariates and therefore improves statistical power. The LS means calculated from this model are the means adjusted for the covariate. LS means are better estimates of true population means compared to arithmetic means. The LS mean difference (netarsudil - placebo) was calculated separately for netarsudil $0.01 \%, 0.02 \%$, and $0.04 \%$ as well as two-sided $p$ values and 95\% confidence intervals (CIs). Superiority for netarsudil concentration $(0.01 \%, 0.02 \%$ and $0.04 \%)$ was concluded if the two-sided $p$ value for testing the LS mean difference (netarsudil - placebo) to 0 was less than 0.05 and the point estimate of the LS mean difference was less than 0 at week 4 . A similar ANCOVA model to the primary variable was used for the analysis of mean diurnal IOP at weeks 1 and 2 and IOP at each post-treatment time point. The change in IOP was tested using a two-sample $t$ test and 95\% $t$ distribution CIs on the difference. Fisher's exact test (two-sided $p$ values) was used to test differences between netarsudil $(0.01 \%, 0.02 \%, 0.04 \%)$ versus placebo for each category (number and percentage of study eyes obtaining a mean diurnal IOP of $\leq 22$ to $\leq 14 \mathrm{mmHg}$, mean diurnal IOP reduction from baseline of $\geq 4$ to $\geq 12 \mathrm{mmHg}$, and mean diurnal IOP percentage reduction from baseline of $\geq 5 \%$ to $\geq 40 \%$ ) at each visit.

The safety analyses were done on the safety population, which included all randomized (as treated) patients who received at least one dose of study medication. The AEs were coded using the Medical Dictionary for Regulatory Activities/Japanese translation version 21.1. The other safety variables were summarized by the descriptive statistics where all continuous study assessments were summarized by number of observations ( $n)$, arithmetic mean, standard deviation (SD), median, and range (minimum, maximum) and the categorical study assessments were summarized by frequency counts and percentages.

The sample size was based on assumptions of a two-sided test with alpha $=0.05$, a common $\mathrm{SD}$ of $3.5 \mathrm{mmHg}$ at each time point yielding a common SD of 3.0 for the mean diurnal IOP, and a correlation among time points of 0.60 . It was estimated that 49 patients per arm in the ITT population would yield at least $90 \%$ power to demonstrate superiority (assuming a difference of at least $2.0 \mathrm{mmHg}$ ) in the mean diurnal study eye IOP of netarsudil $(0.01 \%, 0.02 \%$, or $0.04 \%$ ) to placebo at week 4 . Accounting for approximately $5.0 \%$ discontinuation rate, 52 patients per arm (208 total) were planned for enrollment.

\section{RESULTS}

\section{Demographics and Disposition}

A total of 215 patients were randomized to treatment $(55,54,51$, and 55 patients in netarsudil $0.01 \%, 0.02 \%$, and $0.04 \%$, and placebo groups, respectively). The mean \pm SD age of the overall population was $63.4 \pm 13.2$ years, the majority of subjects were female, and most had POAG across all the treatment groups. There was no statistically significant difference in demographics and other baseline characteristics across the treatment groups (Table 1).

Out of 215 patients, 207 (96.3\%) patients completed 4 weeks of treatment and 8 (3.7\%) patients discontinued the study. Of the eight discontinued patients, six patients discontinued because of AEs (netarsudil $0.01 \%$, one patient [dizziness]; netarsudil $0.02 \%$, one patient [conjunctival hyperemia]; netarsudil $0.04 \%$, four patients [two had conjunctival hyperemia, one had conjunctival hyperemia and blepharitis, and one had superficial punctate keratitis]), one patient discontinued because of withdrawal of consent, and one patient discontinued the study because of lack of efficacy (Fig. 1).

\section{Efficacy}

All 215 patients were included in the primary efficacy analysis (ITT population). The mean of mean diurnal IOP of study eyes at baseline ranged from 20.28 to $21.14 \mathrm{mmHg}$ and showed no statistically significant difference across treatment groups. At week 4, the LS mean of mean diurnal IOP adjusted for baseline of study 
Table 1 Demographics and baseline characteristics (ITT population)

\begin{tabular}{|c|c|c|c|c|c|c|}
\hline Parameter & $\begin{array}{l}\text { Netarsudil } \\
0.01 \% \\
N=55\end{array}$ & $\begin{array}{l}\text { Netarsudil } \\
0.02 \% \\
N=54\end{array}$ & $\begin{array}{l}\text { Netarsudil } \\
0.04 \% \\
N=51\end{array}$ & $\begin{array}{l}\text { Placebo } \\
N=55\end{array}$ & $\begin{array}{l}\text { All patients } \\
N=215\end{array}$ & $p$ value $^{\mathrm{a}}$ \\
\hline \multicolumn{7}{|l|}{ Sex, $n(\%)$} \\
\hline Male & $19(34.5)$ & $25(46.3)$ & $24(47.1)$ & $24(43.6)$ & $92(42.8)$ & 0.5305 \\
\hline Female & $36(65.5)$ & $29(53.7)$ & $27(52.9)$ & $31(56.4)$ & $123(57.2)$ & \\
\hline \multicolumn{7}{|l|}{ Age (years) } \\
\hline Mean \pm SD & $62.7 \pm 14.6$ & $64.1 \pm 12.2$ & $62.0 \pm 13.6$ & $64.6 \pm 12.6$ & $63.4 \pm 13.2$ & 0.7216 \\
\hline \multicolumn{7}{|l|}{ Age category, $n(\%)$} \\
\hline$<65$ & $22(40.0)$ & $23(42.6)$ & $28(54.9)$ & $23(41.8)$ & $96(44.7)$ & 0.4117 \\
\hline$\geq 65$ & $33(60.0)$ & $31(57.4)$ & $23(45.1)$ & $32(58.2)$ & $119(55.3)$ & \\
\hline \multicolumn{7}{|c|}{ Study eye diagnosis, $n$ (\%) } \\
\hline Ocular hypertension & $16(29.1)$ & $15(27.8)$ & $16(31.4)$ & $15(27.3)$ & $62(28.8)$ & 0.9686 \\
\hline $\begin{array}{l}\text { Primary open-angle } \\
\text { glaucoma }\end{array}$ & $39(70.9)$ & $39(72.2)$ & $35(68.6)$ & $40(72.7)$ & $153(71.2)$ & \\
\hline \multicolumn{7}{|l|}{ Prior hypotensive therapy } \\
\hline $\begin{array}{l}\text { No prostaglandin } \\
\text { therapy }\end{array}$ & $36(65.5)$ & $32(59.3)$ & $32(62.7)$ & $28(50.9)$ & $128(59.5)$ & 0.4449 \\
\hline Prostaglandin therapy & $19(34.5)$ & $22(40.7)$ & $19(37.3)$ & $27(49.1)$ & $87(40.5)$ & \\
\hline \multicolumn{7}{|c|}{ Mean diurnal IOP $(\mathrm{mmHg})$ at day 1 (baseline) } \\
\hline Mean \pm SD & $20.51 \pm 2.84$ & $20.28 \pm 2.80$ & $20.76 \pm 3.20$ & $21.14 \pm 3.70$ & $20.67 \pm 3.15$ & 0.5237 \\
\hline
\end{tabular}

ITT intent-to-treat, $N$ number of patients in the given treatment of ITT population, $n$ number of patients in a given category, $S D$ standard deviation

${ }^{a} p$ values are from tests of differences between treatment groups and are two-sided. Fisher's exact test was used for categorical variables and one-way analysis of variance was used for continuous variables

eyes treated with netarsudil $0.01 \%, 0.02 \%$, and $0.04 \%$, and placebo was $16.53,15.82,16.06$, and $18.94 \mathrm{mmHg}$, respectively. The adjusted LS mean difference between netarsudil and placebo (LS mean difference $[95 \% \mathrm{CI}]$ ) was -2.41 $(-3.15,-1.67),-3.12(-3.87,-2.38)$, and $2.88(-3.66,-2.10) \mathrm{mmHg}$ in the netarsudil $0.01 \%, 0.02 \%$, and $0.04 \%$ groups, respectively, with all concentrations achieving statistical significance $(p<0.05$ and the point estimate of the LS mean difference $<0$ ) for the primary endpoint of the study. Similar results were reported at weeks 1 and 2 (Table 2 ).
There was a statistically significantly greater reduction in mean diurnal IOP from baseline in all the netarsudil groups (ranging from 4.10 to 4.56 for $0.01 \%, 4.36-4.80$ for $0.02 \%$, and 4.81-5.14 $\mathrm{mmHg}$ for $0.04 \%$ ) than in the placebo group (ranging from 1.40 to $1.73 \mathrm{mmHg}$ ) at weeks 1,2 , and 4 (all $p<0.0001$ ) (Table 3 ), which corresponded to statistically significantly higher percentage reductions in mean diurnal IOP from baseline in all the netarsudil groups (ranging from $19.8 \%$ to $22.1 \%$ for $0.01 \%$, $21.4-23.5 \%$ for $0.02 \%$, and $23.8-25.1 \%$ for $0.04 \%)$ in comparison with the placebo group 


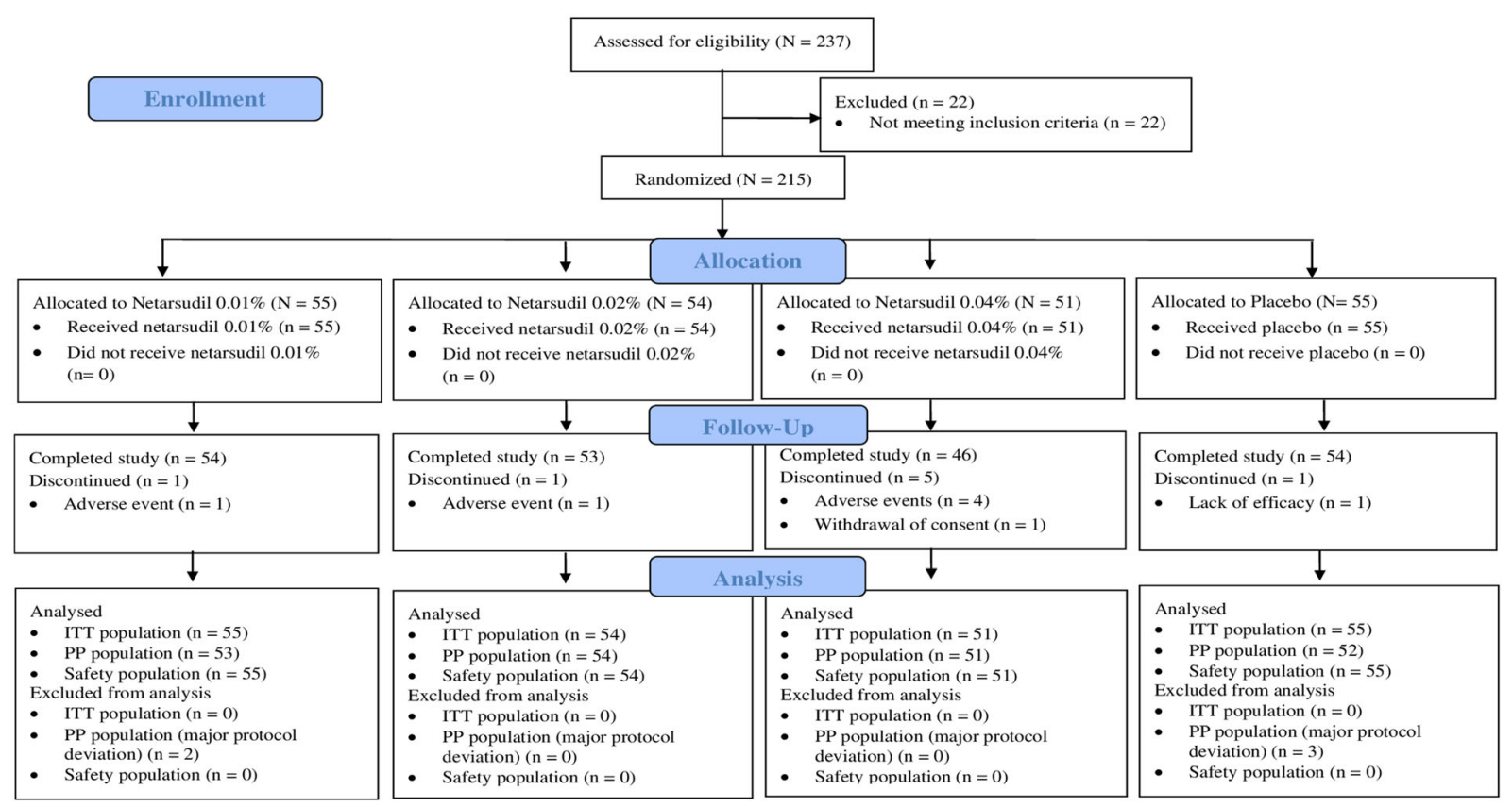

Fig. 1 Study disposition. $N$ total number of patients in the given treatment, $n$ number of patients in a given treatment

$(6.6-8.2 \%)$ at weeks 1,2 , and 4 (all $p<0.0001)$ (Table 4).

The mean IOP was also statistically significantly lower in all the netarsudil groups (ranging from 15.56 to $16.95 \mathrm{mmHg}$ for $0.01 \%$, $15.00-16.32 \mathrm{mmHg}$ for $0.02 \%$, and $15.32-$ $16.62 \mathrm{mmHg}$ for $0.04 \%$ ) when compared with the placebo group (ranging from 18.99 to $19.89 \mathrm{mmHg}$ ) across all post-treatment time points (9 A.M., 11 A.M., and 4 P.м.) at each study visit (all $p<0.0001$ ) (Fig. 2). There was similarly a statistically significantly higher mean reduction and mean percentage reduction from timematched baseline IOP at each post-treatment time point in all the netarsudil groups when compared with the placebo group ( $p=0.0019$ to $<0.0001)$.

In responder analyses, the patients in the netarsudil groups $(0.01 \%, 0.02 \%$, and $0.04 \%$ concentration) generally achieved lower mean diurnal IOP compared to patients in the placebo group at week 4 . The data also showed a greater magnitude of IOP reduction and percentage reduction in mean diurnal IOP from baseline at week 4 for patients treated with all concentrations of netarsudil compared to those treated with placebo (Fig. 3).

\section{Safety}

\section{AEs}

The incidence of AEs was higher among eyes treated with netarsudil, with AEs reported most frequently in the netarsudil $0.04 \%(70.6 \%)$ group compared to the netarsudil $0.01 \%$ (38.2\%), netarsudil $0.02 \%$ (50.0\%), and placebo (9.1\%) groups. All the events were assessed as mild in severity other than two moderate ocular AEs in each of the netarsudil $0.01 \%$ and $0.04 \%$ groups (ulcerative keratitis and osteoarthritis in the netarsudil $0.01 \%$ group [one patient each] and conjunctival hyperemia and eye pain in the netarsudil $0.04 \%$ group [one patient each]). Treatment-related AEs were reported in $27.3 \%$ $(15 / 55)$ in the netarsudil $0.01 \%$ group, $38.9 \%$ $(21 / 54)$ in the netarsudil $0.02 \%$ group, $62.7 \%$ $(32 / 51)$ in the netarsudil $0.04 \%$ group, and $3.6 \%$ $(2 / 55)$ in the placebo group. There were no serious AEs or deaths reported in the study.

The ocular and non-ocular AEs present in at least $5.0 \%$ of patients are summarized in Table 5. The most common ocular AE was conjunctival hyperemia $(n=63)$, with a higher incidence in all the netarsudil groups compared to the placebo group (netarsudil $0.01 \%, 23.6 \%$ 
Table 2 Mean diurnal IOP ( $\mathrm{mmHg}$ ) of the study eye (ITT population, missing data imputed with Monte Carlo Markov chain)

\begin{tabular}{|c|c|c|c|c|c|}
\hline \multicolumn{2}{|l|}{ Visit statistics } & $\begin{array}{l}\text { Netarsudil } \\
0.01 \% \\
N=55\end{array}$ & $\begin{array}{l}\text { Netarsudil } \\
\mathbf{0 . 0 2} \% \\
N=54\end{array}$ & $\begin{array}{l}\text { Netarsudil } \\
0.04 \% \\
N=51\end{array}$ & \multirow{2}{*}{$\begin{array}{l}\text { Placebo } \\
N=55\end{array}$} \\
\hline \multirow{7}{*}{ Week 1} & & & & & \\
\hline & $\mathrm{LS}$ mean $\pm S E$ & $16.39 \pm 0.28$ & $16.22 \pm 0.28$ & $15.69 \pm 0.30$ & $19.34 \pm 0.28$ \\
\hline & Difference from placebo & -2.96 & -3.12 & -3.65 & - \\
\hline & (Netarsudil - placebo) & & & & \\
\hline & $95 \% \mathrm{CI}$ & $(-3.73$ & $(-3.90,-$ & $(-4.45,-$ & - \\
\hline & $p$ value & $-2.19)$ & $2.35)$ & $2.86)$ & \\
\hline & & $<0.0001$ & $<0.0001$ & $<0.0001$ & \\
\hline \multirow[t]{6}{*}{ Week 2} & $\mathrm{LS}$ mean $\pm \mathrm{SE}$ & $16.04 \pm 0.28$ & $16.02 \pm 0.29$ & $15.72 \pm 0.30$ & $19.04 \pm 0.28$ \\
\hline & Difference from placebo & -3.00 & -3.02 & -3.33 & - \\
\hline & (Netarsudil - placebo) & & & & \\
\hline & $95 \% \mathrm{CI}$ & $(-3.79$ & $(-3.82,-$ & $(-4.13,-$ & - \\
\hline & $p$ value & $-2.21)$ & $2.23)$ & 2.53) & \\
\hline & & $<0.0001$ & $<0.0001$ & $<0.0001$ & \\
\hline \multirow[t]{6}{*}{ Week 4 (primary endpoint) } & $\mathrm{LS}$ mean $\pm \mathrm{SE}$ & $16.53 \pm 0.27$ & $15.82 \pm 0.27$ & $16.06 \pm 0.29$ & $18.94 \pm 0.27$ \\
\hline & Difference from placebo & -2.41 & -3.12 & -2.88 & - \\
\hline & (Netarsudil - placebo) & & & & \\
\hline & $95 \% \mathrm{CI}$ & $(-3.15$ & $(-3.87,-$ & $(-3.66,-$ & - \\
\hline & $p$ value & $-1.67)$ & 2.38) & 2.10) & \\
\hline & & $<0.0001$ & $<0.0001$ & $<0.0001$ & \\
\hline
\end{tabular}

$C I$ confidence interval, $I O P$ intraocular pressure, $I T T$ intent-to-treat, $L S$ least squares, $N$ number of patients in the given treatment of ITT population, $S E$ standard error

LS means, SEs, CIs (two-sided), and $p$ values (two-sided) are from ANCOVA model with treatment as a factor and baseline diurnal mean as a covariate (missing data was supplemented by Monte Carlo Markov chain)

[13/55]; netarsudil $0.02 \%, \quad 37.0 \% \quad[20 / 54]$; netarsudil $0.04 \%, 56.9 \%$ [29/51]; placebo, $1.8 \%$ [1/55], $p \leq 0.0009)$. All events of conjunctival hyperemia were assessed as mild except 1 moderate event in the netarsudil $0.04 \%$ group. The majority of conjunctival hyperemia cases (96.8\% [61/63]) were considered as related to the treatment and 4 of 61 treatment-related conjunctival hyperemia cases led to patient discontinuation from the study (netarsudil $0.02 \%$, one patient; netarsudil $0.04 \%$, three patients).
The next most common ocular AEs were eye irritation and conjunctival hemorrhage and were reported only in the netarsudil groups. All cases of eye irritation (netarsudil $0.01 \%, 5.5 \%$ [3/55]; netarsudil 0.02\%, 9.3\% [5/54]; netarsudil $0.04 \%, 3.9 \%[2 / 51])$ and conjunctival hemorrhage (netarsudil 0.02\%, 5.6\% [3/54]; netarsudil $0.04 \%, 5.9 \%$ [3/51]) were assessed as mild. All 10 cases of eye irritation and 3 of 6 cases of conjunctival hemorrhage ( 1 in the netarsudil $0.02 \%$ group and 2 in the netarsudil $0.04 \%$ group) were assessed as related to netarsudil. 
Table 3 Mean change from baseline in mean diurnal IOP $(\mathrm{mmHg})$ of study eye at each post-treatment visit (ITT population, observed data)

\begin{tabular}{|c|c|c|c|c|c|}
\hline \multicolumn{2}{|c|}{ Visit statistics } & \multirow{2}{*}{$\begin{array}{l}\text { Netarsudil } 0.01 \% \\
N=\mathbf{5 5} \\
54\end{array}$} & \multirow{2}{*}{$\begin{array}{l}\text { Netarsudil } \mathbf{0 . 0 2} \% \\
\boldsymbol{N}=\mathbf{5 4}\end{array}$} & \multirow{2}{*}{$\begin{array}{l}\text { Netarsudil } \mathbf{0 . 0 4 \%} \\
\boldsymbol{N}=\mathbf{5 1} \\
48\end{array}$} & \multirow{2}{*}{$\begin{array}{l}\begin{array}{l}\text { Placebo } \\
N=55\end{array} \\
55\end{array}$} \\
\hline Week 1 & $n$ & & & & \\
\hline & Mean \pm SD & $-4.24 \pm 2.02$ & $-4.36 \pm 2.08$ & $-5.14 \pm 2.31$ & $-1.40 \pm 1.97$ \\
\hline & Difference from placebo & -2.84 & -2.97 & -3.74 & - \\
\hline & $(\text { Netarsudil }- \text { placebo })^{\mathrm{a}}$ & & & & \\
\hline & $95 \% \mathrm{CI}$ & $(-3.60,-2.09)$ & $(-3.74,-2.20)$ & $(-4.58,-2.91)$ & - \\
\hline & $p$ value $^{\mathrm{b}}$ & $<0.0001$ & $<0.0001$ & $<0.0001$ & \\
\hline \multirow[t]{6}{*}{ Week 2} & $n$ & 54 & 53 & 48 & 54 \\
\hline & Mean $\pm S D$ & $-4.56 \pm 2.22$ & $-4.58 \pm 2.13$ & $-5.11 \pm 2.43$ & $-1.65 \pm 1.84$ \\
\hline & Difference from placebo & -2.91 & -2.93 & -3.46 & - \\
\hline & $(\text { Netarsudil }- \text { placebo })^{\mathrm{a}}$ & & & & \\
\hline & $95 \% \mathrm{CI}$ & $(-3.69,-2.13)$ & $(-3.69,-2.17)$ & $(-4.30,-2.62)$ & - \\
\hline & $p$ value $^{\mathrm{b}}$ & $<0.0001$ & $<0.0001$ & $<0.0001$ & \\
\hline \multirow[t]{6}{*}{ Week 4} & $n$ & 54 & 53 & 46 & 54 \\
\hline & Mean $\pm S D$ & $-4.10 \pm 2.13$ & $-4.80 \pm 1.82$ & $-4.81 \pm 2.27$ & $-1.73 \pm 1.75$ \\
\hline & Difference from placebo & -2.36 & -3.07 & -3.08 & - \\
\hline & $(\text { Netarsudil - placebo })^{\mathrm{a}}$ & & & & \\
\hline & $95 \% \mathrm{CI}$ & $(-3.11,-1.62)$ & $(-3.75,-2.39)$ & $(-3.87,-2.28)$ & - \\
\hline & $p$ value $^{\mathrm{b}}$ & $<0.0001$ & $<0.0001$ & $<0.0001$ & \\
\hline
\end{tabular}

$C I$ confidence interval, IOP intraocular pressure, ITT intent-to-treat, $N$ number of patients in the given treatment of ITT population, $n$ number of patients at a given visit, $S D$ standard deviation

${ }^{a}$ Difference between the groups (netarsudil - placebo) was tested using $t$-test

${ }^{b} \mathrm{CIs}$ and $p$ values are two-sided

All non-ocular AEs fell into the category of Infections and Infestations, with nasopharyngitis being the most common (netarsudil $0.01 \%$, 0\% [0/55]; netarsudil $0.02 \%, 3.7 \%$ [2/54]; netarsudil $0.04 \%, 5.9 \%$ [3/51]; placebo, $0 \%$ [0/ 55]). All cases of non-ocular AEs were assessed as mild with the exception of one case, which was assessed as moderate (osteoarthritis in the netarsudil $0.01 \%$ group). None of the non-ocular AEs were assessed as related to study drug. No cases of cornea verticillata were reported during the study.

\section{Other Safety Measures}

There were no clinically relevant changes reported in visual acuity for the study eyes or the fellow eyes at any post-treatment visits. There were no statistically significant differences between netarsudil and placebo groups for biomicroscopy findings other than conjunctival hyperemia. The mean of the conjunctival hyperemia score evaluated on a 4-point scale from 0 to 3 at 9 A.M. at week 1, 2, and 4 was $0.2,0.2,0.1$ in the netarsudil $0.01 \%$ group, $0.3,0.2,0.2$ in the netarsudil $0.02 \%$ group, and $0.6,0.4,0.5$ in the netarsudil $0.04 \%$ 
Table 4 Mean percentage change from baseline in mean diurnal IOP of study eye at each post-treatment visit (ITT population, observed data)

\begin{tabular}{|c|c|c|c|c|c|}
\hline Visit stat & istics & Netarsudil $0.01 \%$ & Netarsudil $\mathbf{0 . 0 2 \%}$ & Netarsudil $0.04 \%$ & Placebo \\
\hline Week 1 & $n$ & 54 & 53 & 48 & 55 \\
\hline & Mean \pm SD & $-20.52 \pm 9.00$ & $-21.35 \pm 9.82$ & $-25.14 \pm 10.79$ & $-6.58 \pm 8.64$ \\
\hline & Difference from placebo & -13.94 & -14.77 & -18.56 & - \\
\hline & (Netarsudil - placebo) & & & & \\
\hline & Two-sided 95\% CI & $(-17.29,-10.59)$ & $(-18.29,-11.24)$ & $(-22.36,-14.76)$ & - \\
\hline & $p$ value & $<0.0001$ & $<0.0001$ & $<0.0001$ & \\
\hline Week 2 & $n$ & 54 & 53 & 48 & 54 \\
\hline & Mean \pm SD & $-22.12 \pm 9.98$ & $-22.34 \pm 9.99$ & $-25.07 \pm 11.20$ & $-7.77 \pm 8.26$ \\
\hline & Difference from placebo & -14.34 & -14.57 & -17.30 & - \\
\hline & (Netarsudil - placebo) & & & & \\
\hline & Two-sided 95\% CI & $(-17.84,-10.85)$ & $(-18.08,-11.06)$ & $(-21.14,-13.46)$ & - \\
\hline & $p$ value & $<0.0001$ & $<0.0001$ & $<0.0001$ & \\
\hline Week 4 & $n$ & 54 & 53 & 46 & 54 \\
\hline & Mean \pm SD & $-19.79 \pm 9.38$ & $-23.52 \pm 8.06$ & $-23.80 \pm 11.02$ & $-8.21 \pm 7.95$ \\
\hline & Difference from placebo & -11.58 & -15.31 & -15.58 & - \\
\hline & (Netarsudil - placebo) & & & & \\
\hline & Two-sided 95\% CI & $(-14.90,-8.26)$ & $(-18.37,-12.24)$ & $(-19.36,-11.81)$ & - \\
\hline & $p$ value & $<0.0001$ & $<0.0001$ & $<0.0001$ & \\
\hline
\end{tabular}

$C I$ confidence interval, IOP intraocular pressure, ITT intent-to-treat, $N$ number of patients in the given treatment of ITT population, $n$ number of patients at a given visit, $S D$ standard deviation

Difference between the groups (netarsudil - placebo) was tested using $t$ test

group, respectively, and 0 in the placebo group at all post-treatment visits (Fig. 4). No clinically significant changes in vital signs or laboratory (hematological and blood chemistry) values were reported in any of the treatment groups from baseline to any post-treatment visit. One patient had urinary abnormalities (urine leukocyte esterase positive) at week 4 , which was assessed as mild, unlikely related to the treatment, and was resolved during the study.

\section{DISCUSSION}

In the current phase 2 study, netarsudil ophthalmic solution $0.01 \%, 0.02 \%$, and $0.04 \%$ dosed QD (Р.м.) demonstrated clinically relevant efficacy and met the primary endpoint of superiority to placebo in mean diurnal IOP at week 4 in Japanese patients with POAG or OHT $(p<0.0001)$. In this study population with relatively low baseline mean of mean diurnal IOP ranging from 20.28 to $21.14 \mathrm{mmHg}$, netarsudil $0.01 \%, 0.02 \%$, and $0.04 \%$ achieved mean reductions in mean diurnal IOP at week 4 of 4.10 (19.8\%), 4.80 (23.5\%), and 4.81 (23.8\%) 


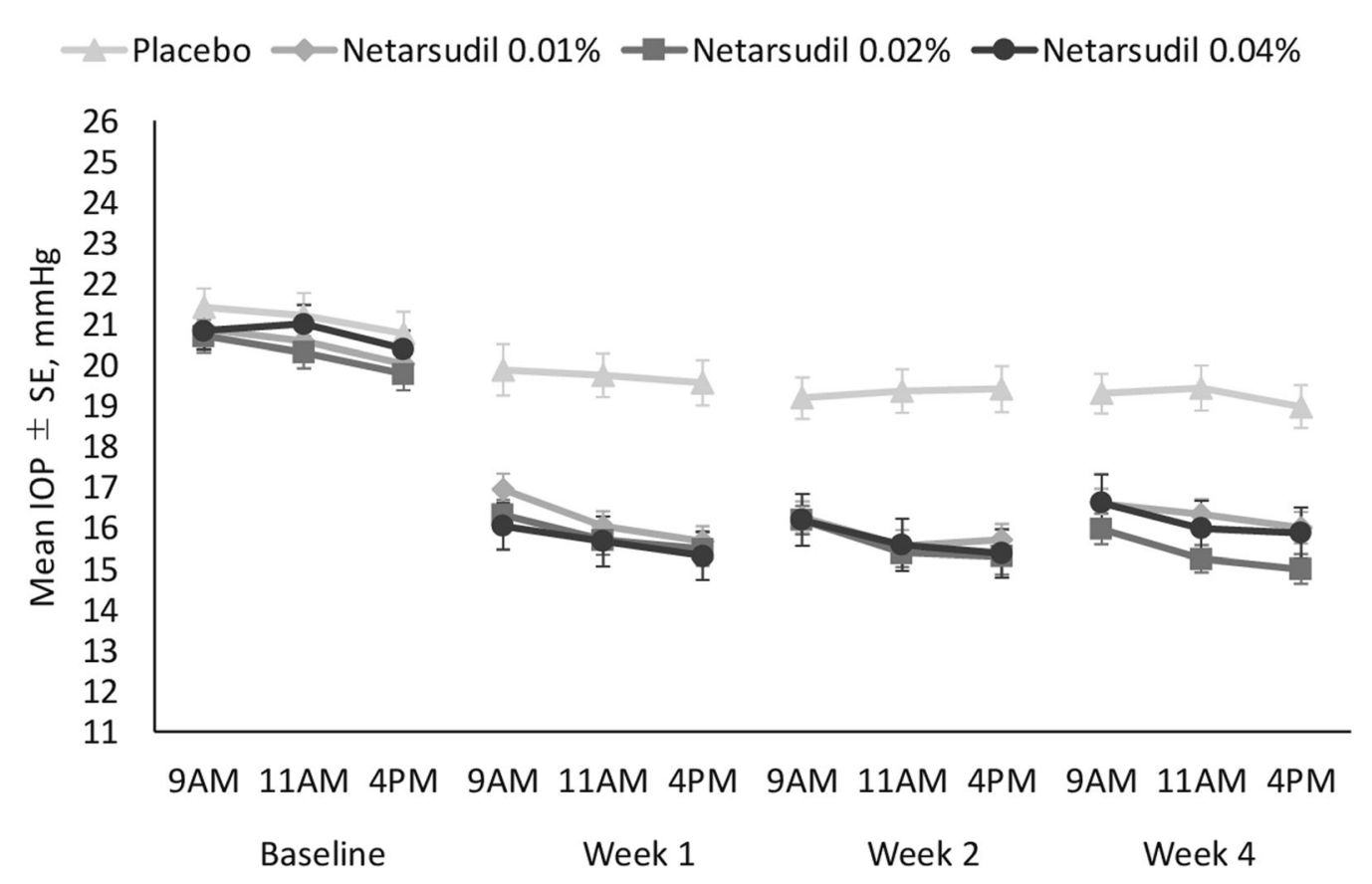

Fig. 2 Mean IOP \pm SE of study eye at each time point ( 9 a.m., 11 a.m., and 4 p.m.) at baseline, week 1, week 2 , and week 4 (ITT population, observed data). IOP intraocular pressure, ITT intent-to-treat, $S E$ standard error
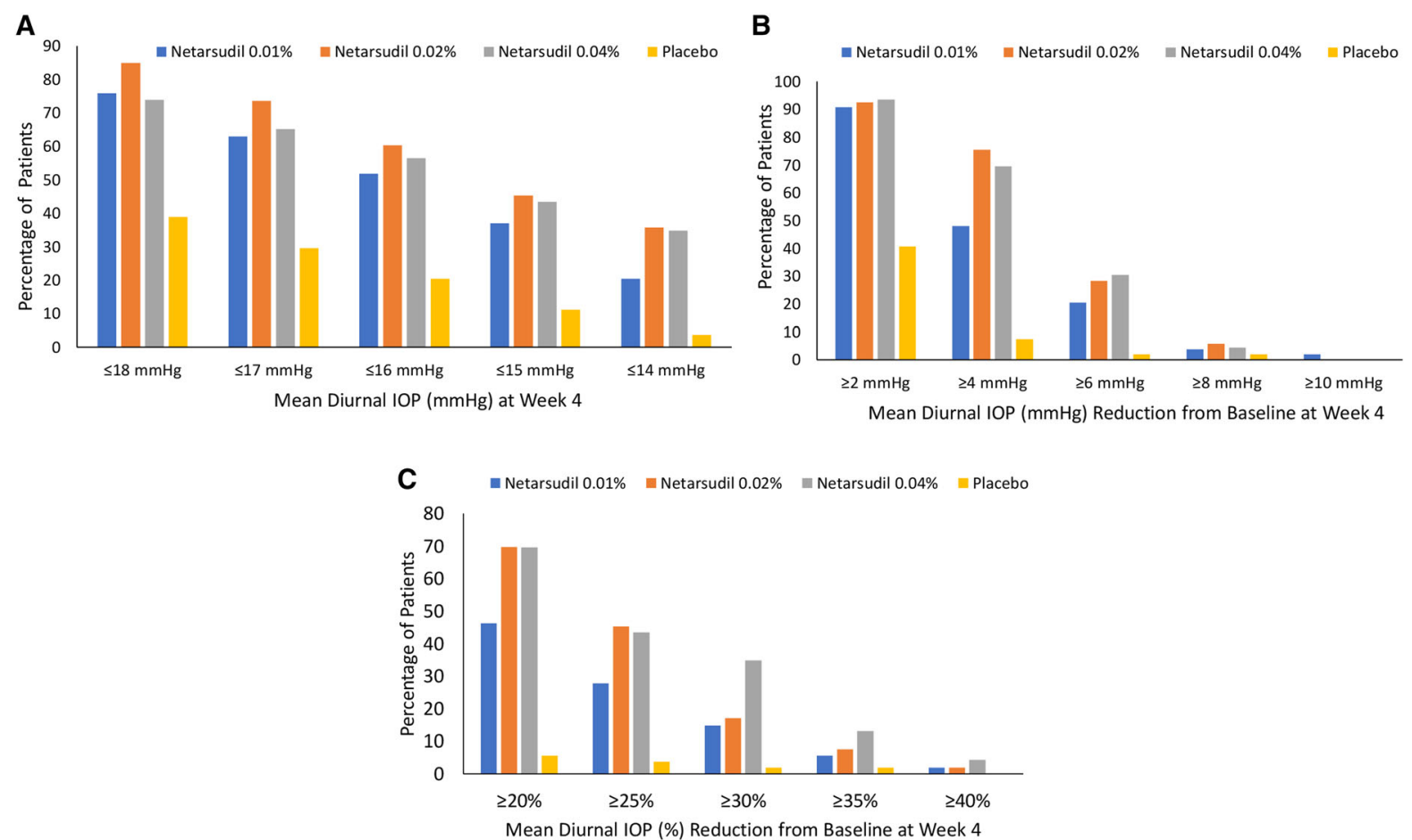

Fig. 3 Percentage of patients with a mean diurnal IOP $\leq 18 \mathrm{mmHg}$ at week 4 , b mean diurnal IOP reduction $\geq 2 \mathrm{mmHg}$ from baseline at week 4 , c mean diurnal
IOP $\geq 20 \%$ reduction from baseline at week 4 in the study eye. IOP intraocular pressure 
Table 5 Ocular and non-ocular AEs in at least $5.0 \%$ of patients in any group (safety population)

\begin{tabular}{|c|c|c|c|c|c|}
\hline \multirow{2}{*}{$\begin{array}{l}\text { System organ class } \\
\text { Preferred term }\end{array}$} & \multicolumn{4}{|c|}{ Number (\%) of patients } & \multirow[t]{2}{*}{$p$ value $^{\mathrm{a}}$} \\
\hline & $\begin{array}{l}\text { Netarsudil } \\
0.01 \% \\
N=55\end{array}$ & $\begin{array}{l}\text { Netarsudil } \\
0.02 \% \\
N=54\end{array}$ & $\begin{array}{l}\text { Netarsudil } \\
0.04 \% \\
N=51\end{array}$ & $\begin{array}{l}\text { Placebo } \\
N=55\end{array}$ & \\
\hline Any ocular AEs & $19(34.5)$ & $23(42.6)$ & $35(68.6)$ & $5(9.1)$ & $\begin{array}{l}0.0022 /<0.0001 / \\
\quad<0.0001\end{array}$ \\
\hline Eye disorders & $17(30.9)$ & $22(40.7)$ & $35(68.6)$ & $4(7.3)$ & $\begin{array}{l}0.0029 /<0.0001 / \\
\quad<0.0001\end{array}$ \\
\hline Conjunctival hyperemia & $13(23.6)$ & $20(37.0)$ & $29(56.9)$ & $1(1.8)$ & $\begin{array}{l}0.0009 /<0.0001 / \\
\quad<0.0001\end{array}$ \\
\hline Eye irritation & $3(5.5)$ & $5(9.3)$ & $2(3.9)$ & 0 & $0.2431 / 0.0271 / 0.2291$ \\
\hline $\begin{array}{l}\text { Conjunctival } \\
\text { hemorrhage }\end{array}$ & 0 & $3(5.6)$ & $3(5.9)$ & 0 & $-/ 0.1182 / 0.1079$ \\
\hline Any non-ocular AEs & $4(7.3)$ & $4(7.4)$ & $5(9.8)$ & $1(1.8)$ & $0.3634 / 0.2057 / 0.1033$ \\
\hline $\begin{array}{l}\text { Infections and } \\
\text { infestations }\end{array}$ & $2(3.6)$ & $3(5.6)$ & $4(7.8)$ & 0 & $0.4954 / 0.1182 / 0.0503$ \\
\hline Nasopharyngitis & 0 & $2(3.7)$ & $3(5.9)$ & 0 & $-/ 0.2431 / 0.1079$ \\
\hline
\end{tabular}

$A E$ adverse events, $N$ number of patients in the given treatment of the safety population

Percentages are based on the number of patients $(N)$ in the given treatment group for the safety population

When reporting incidence, a patient was counted once if they ever experienced an event within the system organ class or individual preferred term more than once

AEs were coded using Medical Dictionary for Regulatory Activities in Japanese (MedDRA/J), version 21.1

${ }^{a} p$ values, expressed as $p 1 / p 2 / p 3$, are from Fisher's exact test comparing the incidence between netarsudil $0.01 \%, 0.02 \%$, and $0.04 \%$ with placebo

$\mathrm{mmHg}$, respectively, that were statistically significantly greater than placebo (1.73 [8.2\%] $\mathrm{mmHg}$ ). In a responder analysis, $20.4 \%, 35.8 \%$, and $34.8 \%$ of patients in the netarsudil $0.01 \%$, $0.02 \%$, and $0.04 \%$ groups, respectively, achieved a mean diurnal IOP of $14 \mathrm{mmHg}$ or less at week 4 compared to $3.7 \%$ in the placebo group. Though all concentrations of netarsudil reduced mean diurnal IOP in comparison to placebo, the overall ocular hypotensive efficacy of netarsudil $0.02 \%$ and $0.04 \%$ were each numerically greater than netarsudil $0.01 \%$.

The ocular hypotensive efficacy of netarsudil $0.02 \%$ shown in the present study is consistent with the results of the phase 3 studies conducted in the USA, in which the IOP-lowering effects of netarsudil $0.02 \%$ QD demonstrated noninferiority to timolol BID [32-34]. In a recent phase 3 study of brimonidine in Japan, where a beta blocker (timolol 0.5\% BID) was used as a comparator, the mean change from baseline in mean IOP of trough (before instillation) and peak ( $2 \mathrm{~h}$ after instillation) at week 4 was $-4.7 \mathrm{mmHg}$ in the timolol (baseline IOP $22.3 \mathrm{mmHg}$ ) [37]. Although the interpretation of the comparison has limitations arising from a cross-study comparison (e.g., different baseline IOPs or no comparable placebo group), a comparable efficacy might be expected between netarsudil $0.02 \%$ QD and timolol BID in terms of IOP reduction for the Japanese population as well. Currently, ripasudil (ripasudil 0.4\% BID) 


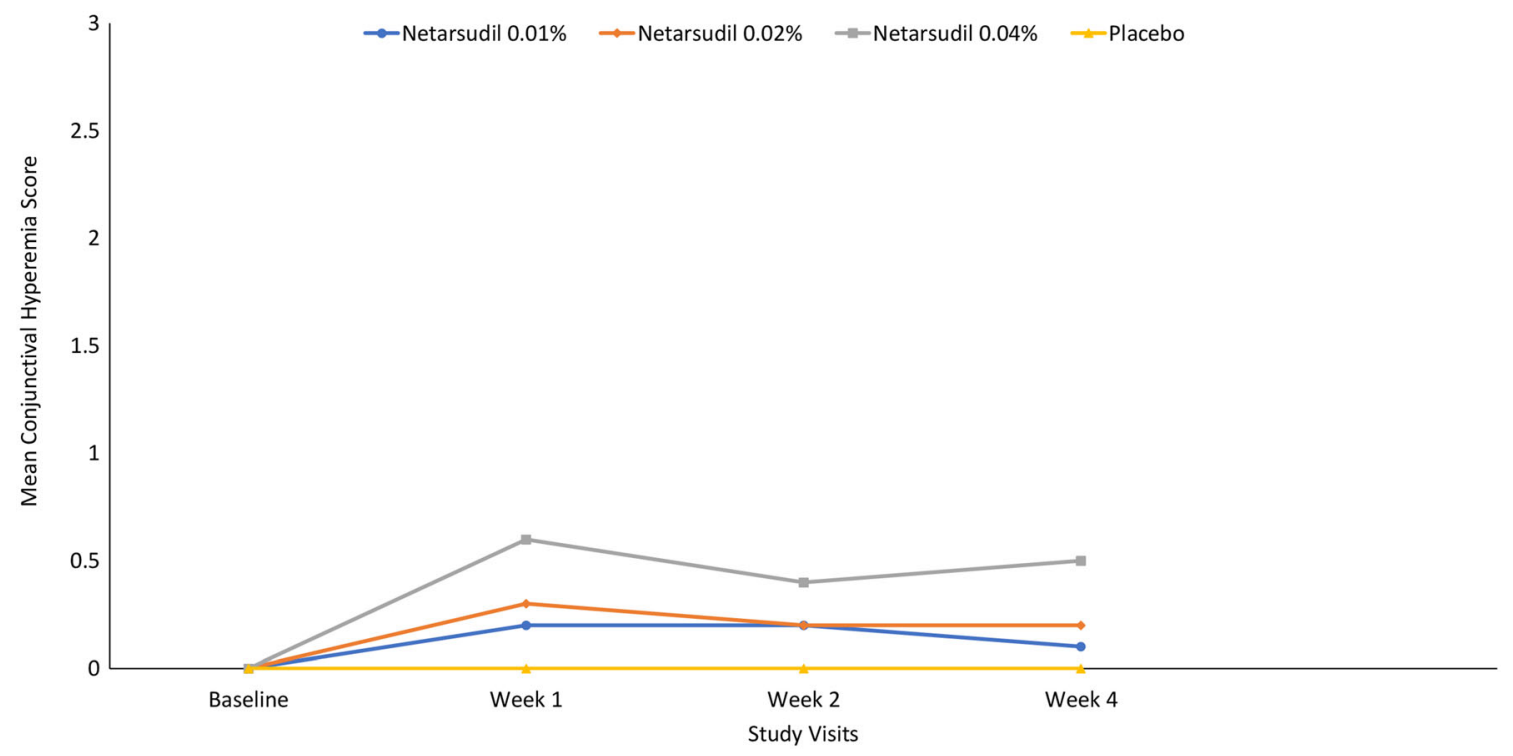

Fig. 4 Mean conjunctival hyperemia score in the study eye at 9 A.M. at baseline, week 1, week 2, and week 4

which belongs to the same ROCK inhibitor class as netarsudil, is approved in Japan as a twicedaily treatment for glaucoma and OHT when other therapeutic agents are not effective or cannot be administered and is broadly used in clinical practice. In a phase 2 dose-response study of ripasudil for patients with POAG or OHT in Japan, patients were treated with ripasudil in concentrations of $0.1 \%, 0.2 \%$, and $0.4 \%$ or placebo BID for 8 weeks [38]. The mean IOP reductions of the last visit (week 8 ) from baseline were $2.2,3.4,3.2$, and $3.5 \mathrm{mmHg}$, respectively, in the placebo, ripasudil $0.1 \%, 0.2 \%$, and $0.4 \%$ groups at before instillation (trough) and $-2.5,-3.7,-4.2$, and $-4.5 \mathrm{mmHg}$ at $2 \mathrm{~h}$ after instillation (peak) with the mean baseline IOP between 23.0 and $23.4 \mathrm{mmHg}$. On the basis of those results, netarsudil $0.02 \%$ QD could have the potential to provide at least comparable ocular hypotensive efficacy to ripasudil $0.4 \%$ BID and to be an alternative option in ROCK inhibitors. Further clinical studies are needed to draw firm conclusions regarding relative efficacy of those IOP-reducing agents.

In terms of safety, netarsudil ophthalmic solutions $0.01 \%, 0.02 \%$, and $0.04 \%$ administered QD were safe and generally well tolerated in Japanese patients with POAG or OHT on the basis of the AEs and assessments of ocular parameters, vital signs, and clinical laboratory findings. The number of patients with at least one $\mathrm{AE}$ was $21(38.2 \%), 27(50.0 \%)$, and $36(70.6 \%)$ in the netarsudil $0.01 \%, 0.02 \%$, and $0.04 \%$ groups, respectively, representing an increased incidence of AEs with higher concentration of netarsudil. In our study, there was no evidence of netarsudil-related serious AEs. The most frequent ocular AE among netarsudiltreated patients in the study was conjunctival hyperemia. Most reports of conjunctival hyperemia were mild (mean conjunctival hyperemia score across netarsudil groups via biomicroscopy was less than 1 at all the time points) and only four patients in netarsudil groups discontinued the study drug because of conjunctival hyperemia (one patient in the netarsudil $0.02 \%$ group and three patients in the netarsudil $0.04 \%$ group). Conjunctival hyperemia is an expected consequence of the known vasodilatory effects of ROCK inhibition $[18,21,39]$. In the phase 3 studies with netarsudil $0.02 \%$, conjunctival hyperemia was the most frequently reported $\mathrm{AE}$ as well, and the proportion of patients with conjunctival hyperemia in the netarsudil $0.02 \%$ QD group ranged from $47.9 \%$ to $61.0 \%$ [32-34, 40], which was higher than that reported in our study (37.0\%). In the phase 2 dose-response study of 
ripasudil mentioned above, conjunctival hyperemia was found in $7(13.0 \%)$ of 54 patients in the placebo group, 23 (43.4\%) of 53 patients in the ripasudil $0.1 \%$ group, $31(57.4 \%)$ of 54 patients in the ripasudil $0.2 \%$ group, and $32(65.3 \%)$ of 49 patients in the ripasudil $0.4 \%$ group [38]. It is important to note that this ocular AE is not specific to ROCK inhibitors and is widely observed in other IOP-reducing agents, most notably prostaglandin analogues and alpha agonists [41]. The other common AEs (occurring in at least $5.0 \%$ of patients in any treatment group) reported in our study, eye irritation and conjunctival hemorrhage, were also reported in the phase 3 studies with netarsudil $0.02 \%$ QD (eye irritation, less than 5.0\%; conjunctival hemorrhage, 13.3-19.5\%) [32-34, 40]. Conjunctival hemorrhage, which was typically described by investigators as small petechial hemorrhages, was reported as mild in all (except one) cases in the study and generally resolved with continued use of netarsudil. Cornea verticillata was a commonly reported ocular $\mathrm{AE}$ in the netarsudil phase 3 studies (netarsudil $0.02 \%$ QD, 5.4-25.5\%) [32-34, 40]. It is a whorllike pattern of benign lipid microdeposits typically localized to the basal corneal epithelium $[42,43]$ which rarely impacts vision and typically resolves upon discontinuation of medication. Consistent with a previous 4-week netarsudil $0.02 \%$ study [35], cornea verticillata was not reported in our study. This may be due to the short duration of our study (4 weeks) since cornea verticillata findings generally have been reported only after 6 weeks or more of treatment. Overall, the safety profile of netarsudil in our study for the Japanese population was consistent with observations from the previous phase 3 studies, with no new safety issues reported.

Our study has a few limitations. The 28-day study duration did not provide information on the long-term efficacy and safety of netarsudil. In addition, there was no comparator ophthalmic hypotensive medication arm in the study.

\section{CONCLUSION}

On the basis of its efficacy and safety profile, netarsudil $0.02 \%$ dosed QD (Р.м.) was confirmed to be the optimal concentration for the Japanese population. The clinically relevant IOP reductions demonstrated in patients with relatively low baseline IOP (mean of mean diurnal IOP at baseline as $20.28-21.14 \mathrm{mmHg}$ ) suggest that netarsudil ophthalmic solution $0.02 \%$ QD may be beneficial in patients with POAG in Japan, where NTG comprises more than $70 \%$ of patients with glaucoma.

\section{ACKNOWLEDGEMENTS}

The authors thank the participants of the study.

Funding. This study, including the Rapid Service Fee and the Open Access Fee, was sponsored by Aerie Pharmaceuticals Ireland Limited.

Medical Writing and/or Editorial Assistance. Medical writing support in the preparation of this article was provided by Gunjan Agarwal of IQVIA and funded by Aerie Pharmaceuticals Ireland Limited. The authors, however, directed and are fully responsible for all content and editorial decisions for this manuscript.

Authorship. All named authors meet the International Committee of Medical Journal Editors (ICMJE) criteria for authorship for this article, take responsibility for the integrity of the work as a whole, and have given their approval for this version to be published.

List of Investigators. Shinshi Chin (Miyagi), Namie Kobayashi (Fukushima), Yuko Shibuya (Saitama), Shima Fukuoka (Saitama), Naoki Hamada (Saitama), Masanori Hangai (Saitama), Kiyoshi Shimizu (Saitama), Kayo Kure (Chiba), Ryoko Okayama (Tokyo), Hiroko Ueda (Tokyo), Motohiro Kiyosawa (Tokyo), Setsuko Hashida (Tokyo), Junko Watanabe (Tokyo), Tamotsu Seki (Tokyo), Takuji Kato (Tokyo), Sakae 
Matsuzaki, (Tokyo), Isao Sato (Tokyo), Tomoyuki Muramatsu (Shizuoka), Yuzuru Yoshimura (Shizuoka), Ryoji Nomura (Aichi), Mitsuko Sugao (Osaka), Akiyasu Kanamori (Hyogo), Hideki Mochizuki (Hiroshima), Genji Nakamori (Fukuoka), Motoyasu Sameshima (Kagoshima).

Prior Presentation. The results of this study were presented at the 74th Annual Congress of Japan Clinical Ophthalmology (web meeting) held from Nov 5 to Dec 6, 2020 JST.

Disclosures. Makoto Araie is a consultant for Pfizer, Santen, Topcon Medical Systems, Senju, Aerie and Kowa, has received lecture fees from Pfizer, Otsuka, Senju and Kowa, and holds patents/royalties with Topcon Medical Systems. Kazuhisa Sugiyama is a consultant for Aerie and has received lecture/manuscript fees from Otsuka, Santen, Senju, Novartis Pharmaceuticals and Bayer. Kenji Aso, Koji Kanemoto, Casey Kopczynski, Michelle Senchyna, David A. Hollander are the employees of and stockholders in Aerie Pharmaceuticals. Kalyani Kothapalli is an employee of Statistics and Data Corporation, a contractor to Aerie.

Compliance with Ethics Guidelines. The study was approved by appropriate ethics committees (Table S1). The study was conducted in accordance with ethical principles based on the Declaration of Helsinki and the guidance stipulated in Article 14, Paragraph 3, and Article 80-2 of the Pharmaceuticals, Medical Devices and Other Therapeutic Products Act of Japan, MHLW Ordinance on Good Clinical Practice (MHLW Ordinance No. 28 [March 27, 1997]), International Council for Harmonization Guideline E6 (R2), the study protocol, and the standard operating procedures. All patients provided the written informed consent prior to their participation into the study.

Data Availability. The analysis results of the current study are available at ClinicalTrials.gov https://clinicaltrials.gov/ct2/show/ results/NCT03844945?term= NCT03844945\&draw=2\&rank=1.
Open Access. This article is licensed under a Creative Commons Attribution-NonCommercial 4.0 International License, which permits any non-commercial use, sharing, adaptation, distribution and reproduction in any medium or format, as long as you give appropriate credit to the original author(s) and the source, provide a link to the Creative Commons licence, and indicate if changes were made. The images or other third party material in this article are included in the article's Creative Commons licence, unless indicated otherwise in a credit line to the material. If material is not included in the article's Creative Commons licence and your intended use is not permitted by statutory regulation or exceeds the permitted use, you will need to obtain permission directly from the copyright holder. To view a copy of this licence, visit http://creativecommons.org/licenses/by$\mathrm{nc} / 4.0 /$.

\section{REFERENCES}

1. Weinreb RN, Aung T, Medeiros FA. The pathophysiology and treatment of glaucoma: a review. JAMA. 2014;311:1901-11.

2. Tham YC, Li X, Wong TY, Quigley HA, Aung T, Cheng CY. Global prevalence of glaucoma and projections of glaucoma burden through 2040: a systematic review and meta-analysis. Ophthalmology. 2014;121:2081-90.

3. Japan Glaucoma Society Glaucoma Practice Guidelines Development Committee. Glaucoma medical care guideline 4 th edition. Nichigankaishi. 2018;122:5-53.

4. Iwase A, Suzuki Y, Araie M, et al. The prevalence of primary open-angle glaucoma in Japanese: the Tajimi study. Ophthalmology. 2004;111:1641-8.

5. Yamamoto T, Iwase A, Araie M, et al. Prevalence of primary angle closure and secondary glaucoma in a Japanese population. Ophthalmology. 2005;112: 1661-9.

6. Pekmezci M, Vo B, Lim AK, et al. The characteristics of glaucoma in Japanese Americans. Arch Ophthalmol. 2009;127:167-71.

7. The AGIS Investigators. The Advanced Glaucoma Intervention Study (AGIS): 7. The relationship between control of intraocular pressure and visual 
field deterioration. Am J Ophthalmol. 2000;130: 429-40.

8. Weinreb RN, Khaw PT. Primary open-angle glaucoma. Lancet. 2004;363:1711-20.

9. Stamer WD, Acott TS. Current understanding of conventional outflow dysfunction in glaucoma. Curr Opin Ophthalmol. 2012;23:135-43.

10. Schwartz K, Budenz D. Current management of glaucoma. Curr Opin Ophthalmol. 2004;15: 119-26.

11. Heijl A, Leske MC, Bengtsson B, et al. Reduction of intraocular pressure and glaucoma progression: results from the Early Manifest Glaucoma Trial. Arch Ophthalmol. 2002;120:1268-79.

12. Kass MA, Heuer DK, Higginbotham EJ, et al. The Ocular Hypertension Treatment Study: a randomized trial determines that topical ocular hypotensive medication delays or prevents the onset of primary open-angle glaucoma. Arch Ophthalmol. 2002;120:701-13 (Discussion 829-30).

13. Kass MA, Gordon MO, Gao F, et al. Delaying treatment of ocular hypertension: the ocular hypertension treatment study. Arch Ophthalmol. 2010;128: 276-87.

14. Collaborative Normal-Tension Glaucoma Study Group. The effectiveness of intraocular pressure reduction in the treatment of normal-tension glaucoma. Am J Ophthalmol. 1998;126:498-505.

15. Bucolo C, Salomone S, Drago F, Reibaldi M, Longo A, Uva MG. Pharmacological management of ocular hypertension: current approaches and future prospective. Curr Opin Pharmacol. 2013;13:50-5.

16. Sambhara D, Aref AA. Glaucoma management: relative value and place in therapy of available drug treatments. Ther Adv Chronic Dis. 2014;5:30-43.

17. Chen J, Runyan SA, Robinson MR. Novel ocular antihypertensive compounds in clinical trials. Clin Ophthalmol. 2011;5:667-77.

18. Kopczynski CC, Epstein DL. Emerging trabecular outflow drugs. J Ocul Pharmacol Ther. 2014;30: $85-7$.

19. Tokushige H, Inatani M, Nemoto S, et al. Effects of topical administration of Y-39983, a selective rhoassociated protein kinase inhibitor, on ocular tissues in rabbits and monkeys. Invest Ophthalmol Vis Sci. 2007;48:3216-22.

20. Wang RF, Williamson JE, Kopczynski C, Serle JB. Effect of $0.04 \%$ AR-13324, a ROCK and norepinephrine transporter inhibitor, on aqueous humor dynamics in normotensive monkey eyes. J Glaucoma. 2015;24:51-4.

21. Rao PV, Pattabiraman PP, Kopczynski C. Role of the Rho GTPase/Rho kinase signaling pathway in pathogenesis and treatment of glaucoma: bench to bedside research. Exp Eye Res. 2017;158:23-32.

22. Tanihara H, Inoue $\mathrm{T}$, Yamamoto $\mathrm{T}$, et al. One-year clinical evaluation of $0.4 \%$ ripasudil (K-115) in patients with open-angle glaucoma and ocular hypertension. Acta Ophthalmol. 2016;94:e26-34.

23. Saito H, Kagami S, Mishima K, Mataki N, Fukushima A, Araie M. Long-term side effects including blepharitis leading to discontinuation of ripasudil. J Glaucoma. 2019;28:289-93.

24. Tsai JC. A comprehensive perspective on patient adherence to topical glaucoma therapy. Ophthalmology. 2009;116:S30-6.

25. Li G, Mukherjee D, Navarro I, et al. Visualization of conventional outflow tissue responses to netarsudil in living mouse eyes. Eur J Pharmacol. 2016;787: 20-31.

26. Lin CW, Sherman B, Moore LA, et al. Discovery and preclinical development of netarsudil, a novel ocular hypotensive agent for the treatment of glaucoma. J Ocul Pharmacol Ther. 2018;34:40-51.

27. Ren R, Li G, Le TD, Kopczynski C, Stamer WD, Gong H. Netarsudil increases outflow facility in human eyes through multiple mechanisms. Invest Ophthalmol Vis Sci. 2016;57:6197-209.

28. Kazemi A, McLaren JW, Kopczynski CC, Heah TG, Novack GD, Sit AJ. The effects of netarsudil ophthalmic solution on aqueous humor dynamics in a randomized study in humans. J Ocul Pharmacol Ther. 2018;34:380-6.

29. Kiel JW, Kopczynski C. Effect of AR-13324 on episcleral venous pressure in Dutch Belted rabbits. J Ocul Pharmacol Ther. 2015;31:146-51.

30. Hoy SM. Netarsudil ophthalmic solution $0.02 \%$ : first global approval. Drugs. 2018;78:389-96.

31. Peace JH, Kopczynski C, Heah TGH. Ocular hypotensive efficacy of netarsudil ophthalmic solution $002 \%$ over a 24-hour period: a pilot study. Investig Ophthalmol Vis Sci. 2017;58:2460.

32. Kahook MY, Serle JB, Mah FS, et al. Long-term safety and ocular hypotensive efficacy evaluation of netarsudil ophthalmic solution: rho kinase elevated IOP treatment trial (ROCKET-2). Am J Ophthalmol. 2019;200:130-7. 
33. Khouri AS, Serle JB, Bacharach J, et al. Once-daily netarsudil versus twice-daily timolol in patients with elevated intraocular pressure: the randomized phase 3 ROCKET-4 study. Am J Ophthalmol. 2019;204:97-104.

34. Serle JB, Katz LJ, McLaurin E, et al. Two phase 3 clinical trials comparing the safety and efficacy of netarsudil to timolol in patients with elevated intraocular pressure. Am J Ophthalmol. 2018;186: 116-27.

35. Bacharach J, Dubiner HB, Levy B, Kopczynski CC, Novack GD, AR-13324-CS202 Study Group. Doublemasked, randomized, dose-response study of AR13324 versus latanoprost in patients with elevated intraocular pressure. Ophthalmology. 2015;122: 302-7.

36. Sherwood MB, Craven ER, Chou C, et al. Twicedaily $0.2 \%$ brimonidine- $0.5 \%$ timolol fixed-combination therapy vs monotherapy with timolol or brimonidine in patients with glaucoma or ocular hypertension: a 12-month randomized trial. Arch Ophthalmol. 2006;124:1230-8.

37. Araie M, Yamazaki Y, Sugiyama K, Kuwayama Y, Tanihara H. Long-term safety and efficacy of brimonidine ophthalmic solution in patients with primary open angle glaucoma or ocular hypertension. Atarashii Ganka (J Eye). 2012;29:679-86.
38. Tanihara $H$, Inoue $\mathrm{T}$, Yamamoto $\mathrm{T}$, Kuwayama $\mathrm{Y}$, Abe H, Araie M, K-115 Clinical Study Group. Phase 2 randomized clinical study of a Rho kinase inhibitor, K-115, in primary open-angle glaucoma and ocular hypertension. Am J Ophthalmol. 2013;156: 731-6.

39. Watabe H, Abe S, Yoshitomi T. Effects of Rho-associated protein kinase inhibitors Y-27632 and Y-39983 on isolated rabbit ciliary arteries. Jpn J Ophthalmol. 2011;55:411-7.

40. Singh IP, Fechtner RD, Myers JS, et al. Pooled efficacy and safety profile of netarsudil ophthalmic solution $0.02 \%$ in patients with open-angle glaucoma or ocular hypertension. J Glaucoma. 2020;29: 878-84.

41. Stewart WC, Kolker AE, Stewart JA, Leech J, Jackson AL. Conjunctival hyperemia in healthy subjects after short-term dosing with latanoprost, bimatoprost, and travoprost. Am J Ophthalmol. 2003;135: 314-20.

42. Mantyjarvi M, Tuppurainen K, Ikäheimo K. Ocular side effects of amiodarone. Surv Ophthalmol. 1998;42:360-6.

43. Hollander DA, Aldave AJ. Drug-induced corneal complications. Curr Opin Ophthalmol. 2004;15: 541-8. 